\title{
INSIGHTS
}

\section{Family reflection: postnatal depression}

\author{
Renee Knight ${ }^{1}$ \\ Pediatric Research (2019) 85:934-935; https://doi.org/10.1038/s41390-019-0377-9
}

\section{PERINATAL ANXIETY AND DEPRESSION AUSTRALIA (PANDA) COMMUNITY CHAMPION}

My first child, Hamish, was born in early 2016. My husband and I were very excited about becoming parents, especially as we had experienced fertility issues and suffered miscarriage.

I had a relatively straightforward pregnancy and when at 38 weeks my labor was induced, I was thrilled to finally realize my dream of becoming a mother. Expecting to feel relieved after Hamish was born, I was shocked to find that I just felt fear. I felt completely overwhelmed and felt that I wasn't up to the task of being a mother and didn't deserve my baby if I couldn't appreciate all I had. I just wanted to wind the clock back.

I was discharged from hospital four days post-birth-despite Hamish not being able to latch and breastfeed. I was fearful he was underweight and that I was a terrible mother for not being able to provide what he needed. My fear quickly turned to anger. I sought professional breastfeeding help from two postnatal support helplines. While they provided breastfeeding advice, unfortunately the helpline staff didn't address my high levels of anxiety.

When my husband returned to work I became more and more desperate for help. I attended the hospital's breastfeeding clinic ten days post birth and finally got the breastfeeding support I needed. Despite my asking for it, this service wasn't offered to me when in hospital and only when I reached out for it. It proved invaluable, as we were able to establish breastfeeding shortly after my first clinical visit.

While I was relieved about finally being able to breastfeed, my mood failed to improve. I felt like I was drowning in responsibility. I spoke with maternal health nurses and other health professionals who assured me that once I got some sleep I would start to feel better. However, as each day rolled into the next things got worse. I began to fear and resent Hamish as I just didn't know how to deal with the unpredictability of having a baby. As I became desperate to get some order and make sense of my feelings I shrank further and further away from the outside world.

I was so overwhelmed with the task of mothering that I often thought about walking away from it all. I had lost my identity and lost myself-I felt like a failure. I thought the darkness was my new reality and that it would last forever.

When Hamish was about six weeks old I became so overwhelmed that I told my husband I wanted to commit suicide. Despite these terrifying thoughts emerging, I knew I needed support immediately. However it took a further two weeks for me to get the right help and it followed countless trips to the family doctor and hospital emergency and home visits from mental health workers.

I was aware that I was suffering postnatal depression and anxiety (PND\&A) and that my condition was worsening quickly, however, the severity wasn't recognized by the health professionals supporting me. At one point I asked the mental health worker to call an ambulance as I didn't want my mother and husband to have to keep caring for me. Yet, we battled on.

My anxiety symptoms were so severe that I very suddenly stopped sleeping and continued in this pattern for ten days in a row, despite taking an anti-depressant and sleeping tablets. A shell of a person, yet I continued to breastfeed my son, refusing to allow the illness to destroy the one role I felt I could perform. After being awake for close to $240 \mathrm{~h}$, and with no end to my insomnia in sight, I turned again to the health professionals to plead for relief. I even asked to be taken to a mental health hospital, I was desperate for my hellish existence to end while also fearful I would die from exhaustion.

Eventually I was finally admitted to a Mother Baby Unit (MBU) a supportive mental health hospital facility for new mothers and their babies. I had been in contact with two family doctors, a psychiatrist, maternal health nurse, and mental health experts for two weeks while living on the edge of suicide. However, it wasn't until I was in the safety of the MBU that I started to get the help I desperately needed. The hospital saved my life.

Hamish and I spent 11 weeks in the MBU, over a four month period. While there I took a daily antidepressant and anxiety medication. I consulted with an on-site psychologist and psychiatrist and practiced mindfulness and meditation. Returning home from such a supportive environment can be difficult and the MBU arranged for in-home care to ensure my ongoing wellness. I continued to take antidepressant medication and to see a psychologist and psychiatrist regularly. The local maternal and child health center arranged for an "enhanced" nurse to visit us weekly and this became a crucial support for me.

I felt mentally well again when Hamish was about eight months old. Sharing my PND\&A story became a key element to my recovery. Speaking with the health professionals involved in my care, they have admitted being surprised at the pace and severity of my illness, and that they were unsure how to get me the right level of support.

Fortunately by acknowledging the illness straight away, I was on the road to recovery much faster than had I tried to fight the illness alone. However, I did feel like it was a long and lonely journey to get help, with a lack of consistent understanding within the medical community of the treatment options.

My hope is for other mothers to seek help early, by raising awareness of this severe illness, and continuing to challenge the stigma surrounding it. For this reason I am a volunteer Community Champion for Perinatal Anxiety and Depression Australia (PANDA). Volunteering provides me with the opportunity to engage with the broader community to share my story and raise awareness and hopefully my doing so will assure PND\&A sufferers that they

\footnotetext{
${ }^{1}$ Perinatal Anxiety and Depression Australia (PANDA) community champion, Melbourne, Australia
}

Correspondence: Renee Knight (info@pedres.org)

Received: 14 March 2019 Accepted: 14 March 2019

Published online: 20 March 2019 
can and should get help as soon as possible, and remind the community that this illness is more prevalent than people think, and it doesn't discriminate.

There is still significant stigma around this illness, such as that women are weak if they experience depression and anxiety, or that they don't love their children. Out of fear of failure and shame, women are often slow to seek help, or don't seek help at all. These problems are compounded when health professionals lack awareness of how to identify and support someone with PND\&A, or how to ensure they receive the right follow-up and referrals.

There needs to be more emphasis on the importance of health professionals assessing parent's mental health during pregnancy and following birth.

Research should focus on addressing the stigma surrounding this illness and raising the awareness of medical professionals of the benefits of early intervention and the steps to achieve it.

The stigma remains that mothers who aren't up to the challenge of parenting are the ones who get PND\&A, and strong women who love their children don't get it. Until research can dispel these myths in terms mothers can understand, they will continue to deny the symptoms, blame it on themselves, and refuse to seek help.

Given family doctors are often the first line of defense for a mother's mental health, it's concerning that they often lack the skills to accurately identify PND\&A and often aren't equipped with how to manage it. It takes many health professionals to ensure recovery, yet we need to investigate why women are falling through the cracks and not reaching for these services.

The longer this illness continues to be stigmatized the risk remains that women don't understand the severity of the illness, or the risk factors and symptoms, and therefore don't seek the appropriate help at the appropriate time.

Governments need to see the benefits of investing in interventions such as Mother Baby Units and the significant difference these facilities make. The biggest risk for children is their parents not being able to access the help and support they need to recover quickly.

We cannot fight the devastating impact of this illness until we fight the stigma that surrounds it. Stigma is leading to people delaying or not getting help, which severely impacts recovery rates and feeds the stereotypes surrounding PND\&A.

Strength of character doesn't shield anyone from this illness, it doesn't discriminate. Research needs to work with consumers from a lived experience perspective, from a broad cross-section of society, to understand the psychological obstacles mothers face in seeking support. They need to show consumers and the medical profession the results of early intervention. 